\title{
POSSIBILIDADES DA EDUCAÇÃO AO AR LIVRE VOLTADA PARA O LUGAR EM UM CONTEXTO BRASILEIRO
}

\section{Possibilities place-based outdoor education in a brazilian context}

\author{
Paola Gomes Pereira* \\ Antonio Carlos Castrogiovanni** \\ * Doutoranda do Programa de Pós-graduação em Geografia da UFRGS \\ E-mail:geografia.paola@gmail.com \\ ** Professor do Programa de Pós-graduação em Geografia da UFRGS \\ E-mail: castroge@ig.com.br
}

\author{
Recebido em 11/08/2020. Aceito para publicação em 16/11/2020. \\ Versão online publicada em 24/11/2020 (http://seer.ufrgs.br/paraonde)
}

\begin{abstract}
Resumo:
Nesse artigo apresentamos a Educação ao Ar Livre, área de estudo presente em países anglo-saxões e germânicos. Através de um diálogo, buscamos maneiras significativas de aplicá-la e verificar sua possibilidade no contexto brasileiro. Para atingir os objetivos da pesquisa, realizamos uma revisão da literatura, considerando conceitos de lugar; educação baseada no lugar e Educação ao $\mathrm{Ar}$ Livre. A partir desse referencial, elaboramos uma série de atividades de Educação ao Ar Livre voltadas ao lugar - no município de Porto Alegre, Brasil, com alunos do segundo ano do Ensino Fundamental, com cerca de sete anos de idade. Essas práticas foram planejadas considerando a chamada Teoria da Mudança, que inclui as ações e os resultados diretos e indiretos, que esperávamos construir. Duas semanas após a realização das atividades aplicamos entrevistas qualitativas semiestruturadas, no formato de grupo focal. Os resultados nos indicam que os alunos participantes do projeto apresentaram mudanças em sua conexão com o lugar, expandindo o seu senso de comunidade e pertencimento, levando à reflexões sobre a sua receptividade ao lugar. Identificamos a diminuição do individualismo dos sujeitos alunos. Pensamos que as análises estabelecidas nesse trabalho, podem oferecer um caminho que venha possibilitar a implementação da Educação ao Ar Livre voltada ao estudo do lugar, considerando as particularidades do nosso país.
\end{abstract}

Palavras-chave: Educação ao Ar Livre; Educação baseada no Lugar; Ensino de Geografia.

\begin{abstract}
:
In this article, we aim to approach Outdoor Education, an area of study mainly present in Anglo-Saxon and Germanic countries. Through a dialogue between Geography and Outdoor Education, we search meaningful ways of applying it and verifying its possibilities in a Brazilian context. To achieve the objectives established in our research, we carried out a literature review, considering the concepts of Place, Place-based Education and Outdoor Education. Considering this framework, we elaborated a week of Place-based Outdoor Education activities in the city of Porto Alegre, Rio Grande do Sul, in southern Brazil, the students that participated of the project attended their second year of elementary school, and had around seven years old. These practices were designed considering a model of theory of change, which included the actions and the direct and indirect results that we expected to emerge from them. Two weeks after carrying out these activities, we applied qualitative semi-structured interviews, in the format of focus groups. The results indicated that the children who participated
\end{abstract}




\begin{abstract}
in the project presented changes in their connection with the place, expanding their sense of community and belonging, and this lead to reflections on their placeresponsiveness. In addition, indirectly, we identified a subtle increase in confidence and a decrease in the students' individualism. We understand that the analyses presented in this work, might offer a way that may enable the implementation of a Place-bases Outdoor Education in Brazil.
\end{abstract}

Keywords: Geography Teaching. Outdoor Education. Place-based Education.

\title{
1. Introdução
}

As ideias presentes nesse trabalho foram construídas numa reflexão, a partir da nossa vivência no curso Transcultural European Outdoor Studies (TEOS), que aconteceu em três países: Reino Unido, Noruega e Alemanha. O diálogo com a Educação ao Ar Livre inglesa, o Friluftsliv norueguês e o Erlebnispädagogik alemão, nos proporcionaram a possibilidade de entender as práticas ao ar livre em uma perspectiva mais ampla (PEREIRA,2015). A partir dessas experiências, inúmeras questões surgiram e a pergunta que permanece conosco é: Como podemos aplicar as noções aprendidas nesses países em um contexto brasileiro? Ao tecer costuras apresentadas em nossas reflexões, não nos parece possível desassociá-las de reflexões e práticas enquanto professores de Geografia que somos. Nossas conclusões provisórias encaminham para ideias que pretendemos explorar com maior amplitude. Através da atividade profissional estabelecemos novas lógicas e formas de enxergar os nossos estudos. Esse é simplesmente um dos caminhos que escolhemos para chegar até aqui e, através desses percursos, entendemos que passamos apenas por pequenos arquipélagos de certezas enquanto navegamos por grandes oceanos de incertezas (MORIN, 1999).

A proposta desse trabalho é investigar as possibilidades de práticas de Educação ao Ar Livre voltadas para o contexto brasileiro e analisar os resultados dos processos de aprendizagem a partir dessas práticas. Entendemos que as atividades ao ar livre voltadas ao lugar apresentam-se como caminho relevante na busca por oferecer aos alunos a possibilidade de fortalecer o seu senso de pertencimento, identidade e comunidade. Ao prepararmos nossas aulas, percebemos que para desenvolver práticas baseadas na compreensão do lugar, pensávamos na pertinência de levarmos os sujeitos para fora da sala de aula. Sendo assim, nos questionávamos: como podemos fortalecer a relação com o lugar se não saímos para os espaços abertos? Como os alunos podem ampliar o senso de lugar se não estão fisicamente/corporalmente envolvidos com esse lugar? De que maneiras estar ao ar livre permite ao sujeito ler e interpretar as diversas faces do global no local? Essas são algumas das indagações que guiaram essa pesquisa.

Observamos uma tendência, na área da Educação ao Ar Livre, em países anglo-saxões, que buscam a presença de práticas voltadas ao lugar, como nas propostas de Wattchow e Brown (2011), e, ao mesmo tempo, constatamos que pensar o ensino de Geografia a partir do lugar, tem sido recorrente para autores como Cavalcanti (2011), Callai (2010) e Castrogiovanni (2010). Dessa forma, percebemos que as duas - Educação ao Ar Livre e a Geografia, podem contribuir entre si de maneira pertinente, permitindo que a Educação ao Ar Livre se

ParaOnde!?, Porto Alegre, v.14, n.1, p.90-109, 2020.http://seer.ufrgs.br/paraonde 
envolva mais com o lugar e que o Ensino de Geografia, baseado no lugar, possa fazer uso de práticas ao ar livre para possibilitar experiências de ensino e aprendizagem mais significativas. As narrativas de jornadas e excursões de heróis são bastante presentes nas tradições europeias de Educação ao Ar Livre (LOYNES, 2010) e possuem seu valor em diferentes momentos do desenvolvimento de crianças e adolescentes. Porém, uma vez que eles percorrem essas jornadas de transformação individual, é importante que em outras oportunidades tenham a chance de desenvolver um senso de lugar, que inclua noções de pertencimento e identidade. Os sujeitos alunos são capazes de entender o seu lugar, entender que as suas ações trazem consequências para esses lugares. Mais do que isso, desenvolvem um senso de lugarização que torna possível transformar os espaços geográficos (re)construídos por eles.

A partir das premissas, indicamos que o principal objetivo estabelecido para este trabalho é desenvolver e aplicar práticas de Educação ao Ar livre voltada ao lugar, dialogando com as experiências e a Educação ao Ar Livre do Reino Unido. Na busca por respondermos a esse objetivo, nossos objetivos específicos são:

- Fazer uma revisão da literatura sobre os tópicos relacionados à Educação ao Ar Livre voltada ao lugar;

- Caracterizar o perfil dos alunos participantes do projeto;

- Construir práticas de Educação ao Ar Livre voltadas ao lugar no contexto brasileiro;

- Interpretar os resultados obtidos através dessas práticas.

\section{Desenvolvimento}

Entendemos que o mundo passa por um processo de globalização (SANTOS, 2004) onde pressupostos e ações globais influenciam na perda de identidades locais. Nessa situação, percebemos que os locais tendem a se tornarem mais difusos. Frequentemente torna-se difícil a leitura da materialidade do local no global. Ao mesmo tempo, sabemos que, em um cenário paradoxal, podemos ver o surgimento de novos localismos como uma resposta ao processo de homogeneização imposta pelo globalismo.

As noções de lugar que orientam a área de Educação ao Ar Livre buscam um diálogo com autores da Geografia. Para refletirmos sobre esse conceito abordamos ideias apresentadas por Tuan $(1980,2001)$ e Massey $(2001,2005)$. Entendemos o lugar, através das lentes de Tuan (1980, 2001), entendido como parte do espaço que é vivido e que tem como característica central a identidade. O lugar é produzido por e pelos sujeitos e, ao mesmo tempo, reproduz as relações entre espaço e sociedade. Além disso, pensamos que essas noções estão ligadas ao fortalecimento de um sentimento que conduz à identidade. Identidade que emerge das relações do espaço e da sociedade formando um único espaço - o lugar.

Massey (2001, 2005), aborda o Lugar como local de encontro da realidade de vidas cotidianas. A autora lembra que esse lugar (muitas vezes abordado como lugar-local) propaga-se mais longe do que pensamos, e nos convida a entender o lugar não apenas como o local, mas presente à noção de que nesse espaço vivido são apresentadas diversas faces do global, e por isso para Massey

ParaOnde!?, Porto Alegre, v.14, n.1, p.90-109, 2020.http://seer.ufrgs.br/paraonde 
(2005) o lugar aparece como lugares de encontro, como eventualidade. Nós diríamos de (des)encontros!

Em sua análise, a autora traz um ponto substancial ao questionar como podemos preservar a singularidade de um lugar e manter a ideia de especificidade espacial. Pensamos estar aqui um dos desafios de uma Educação ao Ar Livre voltada ao lugar, incorporar essas práticas e ações. Este processo não deve produzir localismos excludentes que não permitam enxergarmos codependência enquanto lugares. Através de Massey (2005), relembramos a importância de compreendermos que para existirmos enquanto lugar, outros lugares também são necessários, no que a autora denomina um senso de lugar sem fronteiras, sem limites. Nessa perspectiva, destacamos a importância de conectar o local e o global. Entendendo que as relações e as experiências se expressam em uma escala maior do que imaginamos. Sob tal ótica, lembramos que enquanto lugares e sujeitos somos pontos de encontro de redes mais amplas de conexões, e que para existirmos como um lugar, precisamos nos relacionar com os outros.

Wattchow e Brown (2011), propõem uma ideia de sermos responsivos (Place Responsive em inglês) ao lugar, que inclui a noção de que não apenas pertencer e conectar-se ao lugar é importante, mas também entender que as ações tomadas por nós possuem respostas, consequências, possuem um efeito nesse local. Enxergando o mundo como proposto por Bauman (2000), onde há fluidez de sentimentos, se traduz, de forma mais acentuada nas experiências e nos relacionamentos na vida dos sujeitos dos grandes centros urbanos. Um mundo pós-moderno, onde as crianças estão acostumadas a equipamentos como televisores e computadores, que influenciam essa liquidez das relações entre as pessoas e entre as pessoas e a terra. Os alunos se acostumam a um mundo abstrato, onde cada vez é mais difícil vivenciar situações e experiências palpáveis. Templos de consumo são criados e neles a vida é feita a crédito, sempre há algo que o indivíduo precisa possuir. Essa realidade está presente no contexto brasileiro e reforça a pertinência de práticas ao ar livre, de interagir com o espaço materializado, de criar possibilidades de ação.

Ao observarmos a Base Nacional Comum Curricular (BNCC) (BRASIL, 1997 e 2018), percebemos que dentre as habilidades geográficas propostas para alunos dos anos iniciais do Ensino Fundamental contemplam noções como:

\begin{abstract}
A ênfase nos lugares de vivência, dada no Ensino Fundamental - Anos Iniciais, oportuniza o desenvolvimento de noções de pertencimento, localização, orientação e organização das experiências e vivências em diferentes locais. Essas noções são fundamentais para o trato com os conhecimentos geográficos. Mas o aprendizado não deve ficar restrito apenas aos lugares de vivência. Outros conceitos articuladores, como paisagem, região e território, vão se integrando e ampliando as escalas de análise. De maneira geral, na abordagem dos objetos de conhecimento, é necessário garantir o estabelecimento de relações entre conceitos e fatos que possibilitem o conhecimento da dinâmica do meio físico, social, econômico e político. Dessa forma, deve-se garantir aos alunos a compreensão das características naturais e culturais nas diferentes sociedades e lugares do seu entorno, incluindo a noção espaço-tempo. (BRASIL, 2018, p. 368).
\end{abstract}

ParaOnde!?, Porto Alegre, v.14, n.1, p.90-109, 2020.http://seer.ufrgs.br/paraonde 
Esses objetivos estão próximos dos objetivos que pensamos para este exercício de pesquisa: refletir como a Educação ao Ar Livre voltada para o lugar pode trabalhar em conjunto com as propostas curriculares nacionais. Por isso, não compreendemos como necessário o rompimento com a forma como a educação é pensada no país, mas sim, buscamos uma possibilidade de diálogo. Os objetivos apresentados pelos documentos oficiais trazem noções como o sentimento de confiança, o exercício da cidadania, o uso da linguagem corporal, a cooperação, a busca de decisões coletivas, e pensamos que todos estes estão ligados às práticas aplicadas neste projeto.

Com o objetivo de construirmos pontes que possam criar possibilidades para nosso contexto, dialogamos com um projeto que ocorreu na Escócia. O estudo é proposto por Mannion, Addey e Lynch (2010) e pensa a Educação voltada ao lugar, onde escolas, comunidades e natureza se encontram. A pesquisa apresenta dois estudos de caso diferentes: um com alunos do ensino fundamental e outro com alunos do ensino médio. Nosso foco aqui é no primeiro grupo. Uma vez que essa é a faixa planejada para nossa pesquisa. Outro ponto relevante para pensarmos o estudo, é o fato de ter sido desenvolvido em uma escola urbana, assim como a nossa.

O estudo com o qual dialogamos, trabalhou em uma escola que tinha um projeto aprovado pelo governo escocês e, portanto, possuía um orçamento que foi aplicado nas ações. Nele, por exemplo, apareciam atividades específicas, como a identificação de plantas. Esse não era o objetivo do trabalho, mas isso, inspirou uma de nossas atividades. Observamos algumas noções compartilhadas como o aprendizado sensorial, a presença da sustentabilidade ambiental e do bem-estar da comunidade, indicando práticas baseadas nos lugares, que podem ser aplicadas em diferentes contextos. Uma das ideias substanciais no trabalho de Mannion, Addey e Lynch (2010) é que as escolas são encorajadas a contextualizar mais os currículos nacionais e a recorrer a recursos e sujeitos locais. Leva em consideração o seu ambiente e as suas relações sociais, e essa nos é relevante inspiração, traduzir orientações de nível nacional e adaptá-las às características locais.

O projeto apresentado, aplicado em uma escola pública, localizada no município de Porto Alegre. Ela está localizada em um bairro próximo ao centro da cidade. Pensamos o trabalho de forma direta, para que outros professores em situações similares possam aplicar propostas semelhantes, sem necessidade de um orçamento diferenciado da realidade de escola pública. Como observamos nas fotografias a seguir (Figuras 1, 2, 3 e 5) os alunos não tinham roupas específicas para atividades ao ar livre. Lembramos que o projeto foi aplicado durante o outono, no mês de junho. Havia um excesso de umidade no ar, dificultando algumas escolhas, e dessa forma, as práticas foram adiadas duas vezes..

Após a realização das práticas, foram aplicadas entrevistas semiestruturadas com um grupo de respondentes, no formato de grupos focais, pensamos essa técnica de pesquisa através da leitura de Bauer e Gaskell (2012) e Flick (2011). Para as entrevistas, dividimos a turma de segundo ano do Ensino Fundamental em três grupos. Entendemos que os grupos focais, permitem os sujeitos alunos a participação na discussão e interação, proporcionando novas

ParaOnde!?, Porto Alegre, v.14, n.1, p.90-109, 2020.http://seer.ufrgs.br/paraonde 
leituras sobre o tema abordado. Além disso, os grupos focais são mais que a soma de suas partes, pois, ao longo dos diálogos, podem ocorrer mudanças de opinião e formas de enxergar a situação. Os grupos focais oferecem um envolvimento emocional diferenciado de outros formatos de entrevista. Os participantes se expressam através de novas lógicas e vão além em suas leituras e avaliações sobre o que está sendo pensado. Os grupos focais que apresentamos nessa pesquisa são grupos naturais, uma vez que os alunos eram colegas e se conheciam previamente. Eles foram divididos de forma aleatória. Por estarmos lidando com sujeitos que frequentam a mesma escola e de faixa etária similar, podemos dizer que eram grupos homogêneos. A moderação foi substancial, considerando que, além de serem pensadas perguntas orientadoras, lidamos com sujeitos alunos jovens, logo, nos foi exigida uma necessidade maior de organização para a moderação. (BAUER e GASKELL, 2012; FLICK, 2011).

Figura 1- Área onde o projeto foi aplicado, avenida atravessada pelos sujeitos alunos e margem do Lago Guaíba.

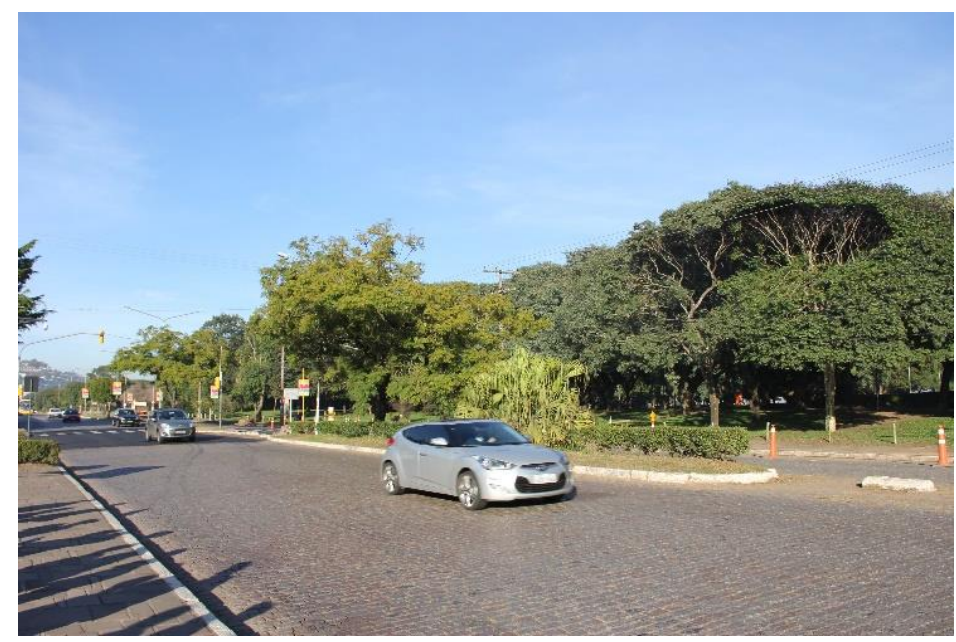

Fonte: Paola Gomes Pereira; Antonio Carlos Castrogiovanni (2020)

Figura 2 - Área onde o projeto foi aplicado, avenida atravessada pelos sujeitos alunos e margem do Lago Guaíba.

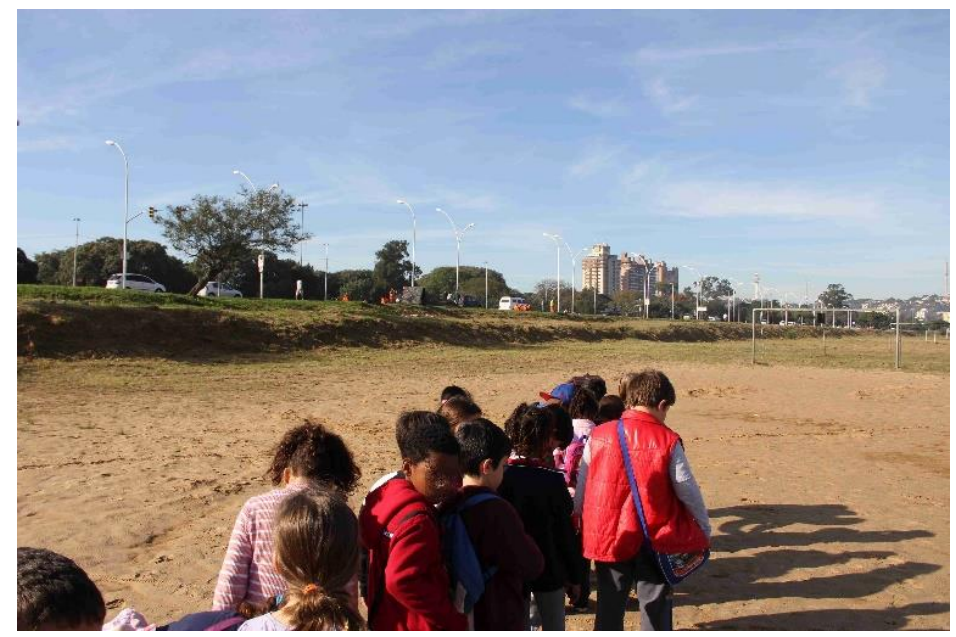

Fonte: Paola Gomes Pereira; Antonio Carlos Castrogiovanni (2020)

ParaOnde!?, Porto Alegre, v.14, n.1, p.90-109, 2020.http://seer.ufrgs.br/paraonde 
As características do tempo atmosférico, surge como um dos diálogos culturais interessantes em nossa leitura. Em um primeiro momento pareça algo simples, ao buscarmos relacionar a situação da umidade e chuvas constantes com as experiências prévias no Reino Unido (e depois na Noruega e na Alemanha) percebemos diferenças acentuadas. Nesses países, a chuva (ou até mesmo a neve) é constante, e também as temperaturas baixas. Dessa forma, experienciamos inúmeras situações em que mesmo o tempo frio e chuvoso não foi considerado como motivo para a não realização da atividade ao ar livre. Diferente da nossa realidade no Brasil, na qual estamos acostumados à noção de que caso chova, os planos de ir para a rua e as viagens são canceladas, sempre que possível.

A explicação mais razoável para essa situação são as características climáticas locais, pois, embora no clima de Porto Alegre exista uma boa quantidade de precipitação ao longo do ano, é muito raro que a cidade tenha tantos dias consecutivos de chuva como, por exemplo, no Norte do Reino Unido. Essa reflexão nos traz aspectos transculturais interessantes, pois, após morar no Reino Unido por seis meses, percebemos que se não fazemos uma saída de campo devido ao tempo estar chuvoso, pode ser que tenhamos que adiá-la por um longo período. Mesmo que tenhamos nos acostumado a essa maneira de lidar com o tempo em nossas experiências pessoais, em um contexto brasileiro seria muito difícil convencer os pais dos alunos a deixá-los sair em um dia chuvoso. Então esperamos mais duas semanas e executamos o projeto um pouco mais tarde do que o planejado. Após duas semanas chuvosas, o chão ainda estava um pouco molhado, o que proporcionou algumas das aventuras que seguirão. Isso nos remete a ideia de que o inesperado muitas vezes pode gerar possibilidades de aprendizagem significativas, mas, enquanto professores, sabemos das dificuldades e desafios para lidarmos com situações não planejadas.

O grupo de alunos tinha entre seis e sete anos e cursava o segundo ano do ensino fundamental, o que significa que estavam trabalhando em seu processo de alfabetização. A escolha dessa faixa etária foi considerando as habilidades e competências prévias e posteriores previstas pelos Parâmetros Curriculares Nacionais (BRASIL, 1997). O grupo foi acompanhado pela professora da turma e pela pesquisadora. Aplicamos também uma atividade de desenho antes e uma depois da semana de práticas na qual orientamos a desenharem os seus locais favoritos próximos à escola. A análise desses desenhos não serão apresentados, pois nesse artigo escolhemos focar nas informações geradas através dos grupos focais.

Para orientarmos trabalho, criamos um instrumento baseado na ideia da Teoria da Mudança proposto por McNeil, Reeder e Rich (2012). Neste gráfico, é possível observar a continuidade da linha de pensamento que conduziu estudo e suposições que tínhamos antes da aplicação das atividades. Para construir o modelo, partimos das observações feitas com os sujeitos alunos na sala de aula regular que conduziram para as práticas de Educação ao Ar Livre, e quais o resultados esperados. A partir dessas atividades, em seguida, pensarmos em quais resultados indiretos poderiam surgir com de tais ações, como podemos observar na figura 3.

ParaOnde!?, Porto Alegre, v.14, n.1, p.90-109, 2020.http://seer.ufrgs.br/paraonde 
Figura 3 - Modelo de Teoria da Mudança planejado

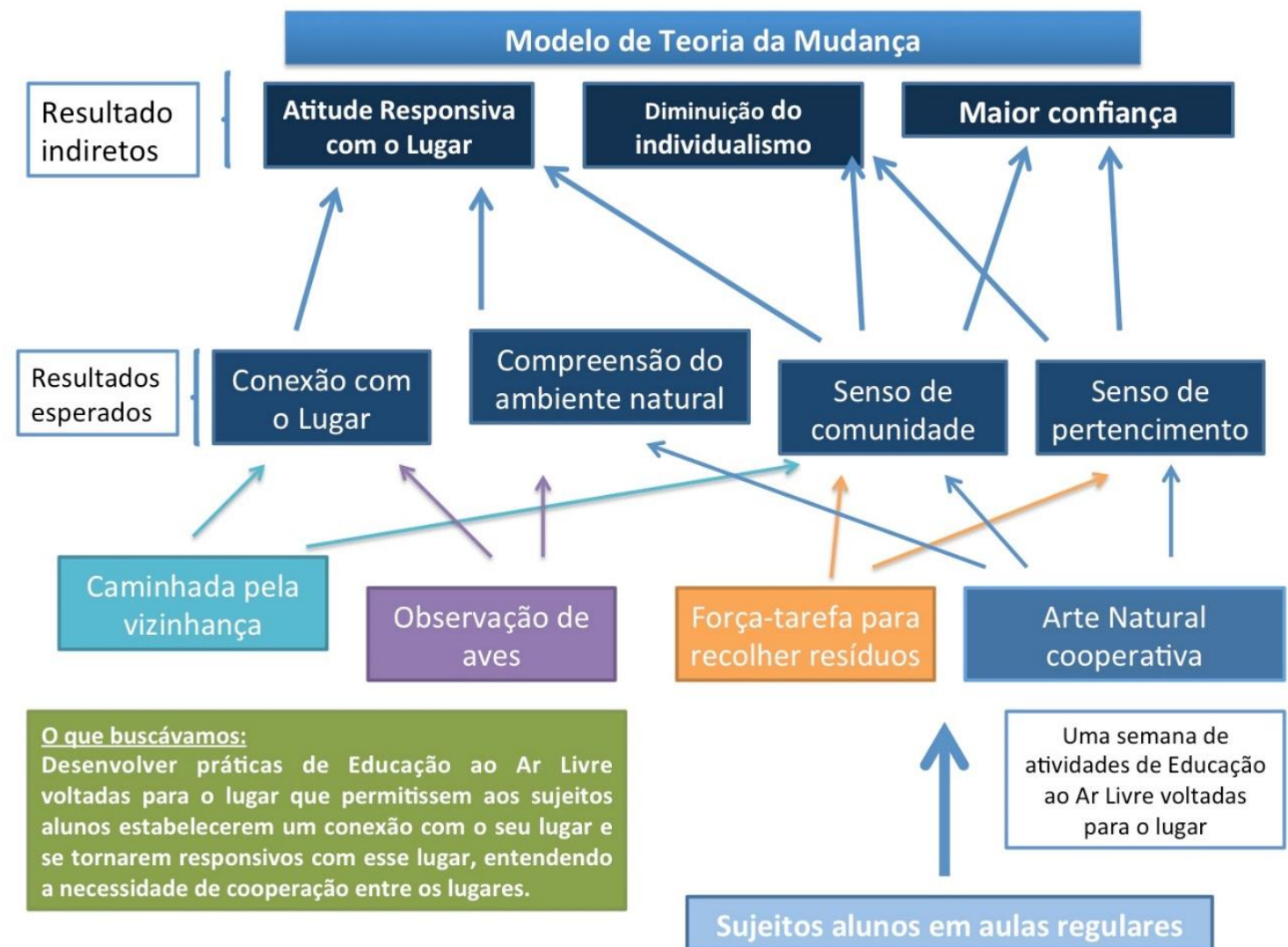

Fonte: Paola Gomes Pereira (2020)

Os diferentes momentos do projeto foram planejados por nós. Algumas sugestões foram feitas pela professora da turma, considerando particularidades e necessidades específicas dos alunos. Os planos consideraram o que gostaríamos que as crianças desenvolvessem durante a aplicação da proposta, quais seriam as metodologias pensadas para colocar em prática e que permitiriam que os sujeitos alunos desenvolvessem as habilidades planejadas e quais atividades que as caracterizariam. Algumas adaptações precisaram ser realizadas para tornar o projeto viável. Ao lidarmos com a realidade escolar, sabemos que as mudanças são constantes.

Inicialmente, o projeto havia sido pensado para ter cinco dias de atividades. Porém, devido a algumas preocupações da escola e da professora, foi possível chegarmos a três dias de atividades fora da escola, um dia no pátio e um último dia dedicado para reflexões sobre as práticas. Entendemos que tal situação nos mostra alguns obstáculos que podem surgir quando tentamos aplicar práticas diferentes das atividades comuns. Quando fizemos a proposta, a diretora e a professora nos informaram que não seria possível passar cinco dias fora da área da escola. Após dialogarmos e compartilharmos a relevância das atividades, conseguimos alcançar um equilíbrio ao definirmos três dias de atividades fora da escola. Até mesmo as atividades no pátio da escola eram uma preocupação

ParaOnde!?, Porto Alegre, v.14, n.1, p.90-109, 2020.http://seer.ufrgs.br/paraonde 
para a diretora e para a professora. Elas mencionaram que isso poderia perturbar outras turmas e grupos que teriam aulas de educação física no pátio durante esse período. A principal preocupação da escola é que, quando você está com as crianças em outros espaços, existem mais questões com as quais precisamos nos preocupar em relação à segurança. Entendemos que isso é compreensível; visto que, mesmo quando estamos trabalhando como professores de Geografia, sabemos da responsabilidade de tomarmos decisões como essa de levar grupos para fora do espaço escolar.

Com a experiência do curso Transcultural European Outdoor Studies (TEOS), mestrado realizado em países europeus, percebemos como ocorre de forma mais tranquila em outros países. Devido à frequência dessas atividades, elas acabam tornando-se mais naturais para professores, pais e alunos. Refletimos que deva existir um processo de transição para nos acostumarmos com diferentes práticas ao ar livre, e ele pode ser suave, quando feito aos poucos e dando tempo aos pais e professores para se acostumarem com essas novas práticas. Apresentaremos as quatro atividades listadas no modelo da Teoria da Mudança e mencionaremos alguns outros momentos relevantes das práticas. Optamos por resumir a exposição das atividades, para tornar o texto mais agradável aos leitores.

Apresentamos na Figura 4 alguns dos locais visitados ao longo do projeto. Lembramos que a área representada está próxima ao centro da cidade de Porto Alegre (aproximadamente $2 \mathrm{~km}$ ao Sul), e que a Avenida Ipiranga é uma das principais vias do município, traçada na direção leste-oeste. Na imagem, o número 1 indica o parque onde ocorreu o primeiro dia de atividades. Entre ele e a escola temos aproximadamente um quilômetro de distância. O número 2 apresenta a margem do Lago Guaíba onde ocorreu o segundo dia de atividades. O número 7 é o Lago Guaíba. O número 3 é uma pequena praça atrás da escola, que chamaremos de Praça 1. O número 4 é outra praça próxima ao parque, que chamaremos de Praça 2. O número 5 é um grande Shopping Center próximo à escola. O número 6 é o Arroio Dilúvio, que atravessa a cidade de Leste a Oeste e que esperávamos explorar no projeto, mas que devido à mudança no planejamento do número de dias, foi retirado do projeto.

No primeiro dia, levamos as crianças a um dos parques da cidade (número 2 na Figura 4). Próximo à escola (cerca de um quilômetro de distância), andamos pelo bairro e aproveitamos esse tempo para explorarmos o olhar e descobrir os elementos da paisagem. Apesar de alguns autores como Wattchow e Brown (2011) mencionarem que esse tipo de atividade (conhecer a vizinhança) não necessariamente é o que se sugere para uma Educação ao Ar Livre voltada para o lugar. No entanto, lembrando o contexto brasileiro, consideramos importante, sermos capazes de nos adaptar à realidade do que nos é oferecido, ponderando os materiais e o tempo disponíveis. Entendemos que uma atividade como essa pode parecer simples, em um primeiro momento, mas precisa de um preparo e estudo do professor. Ela tem diversas potencialidades para oferecer processos de aprendizagem representativos para os alunos lerem o espaço geográfico.

ParaOnde!?, Porto Alegre, v.14, n.1, p.90-109, 2020.http://seer.ufrgs.br/paraonde 
Figura 4 - Imagem dos locais das atividades

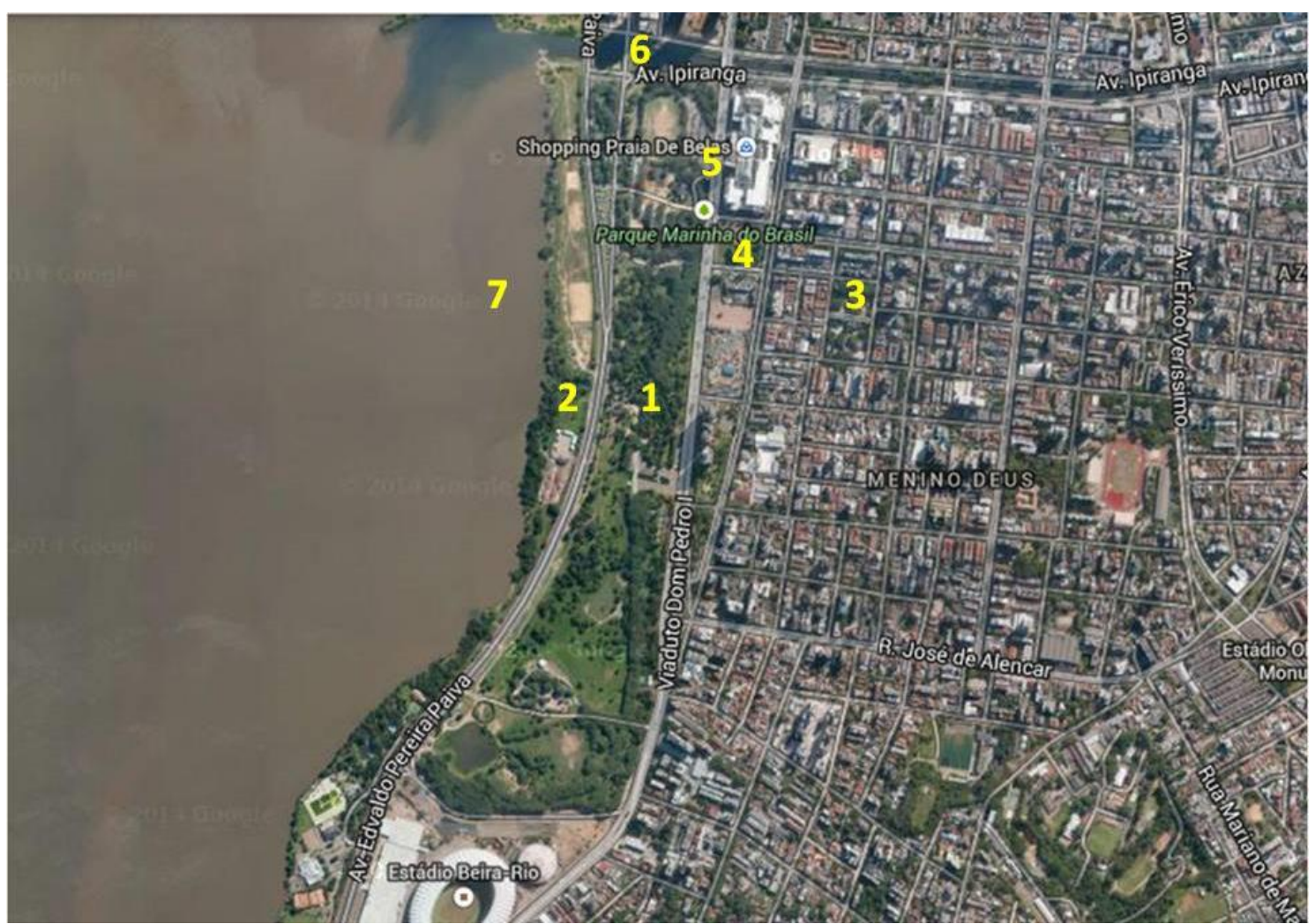

Fonte: Google Earth editado pela autora (2020)

A principal preocupação de Wattchow e Brown (2011) é o fato da atividade estar geralmente vinculado a disciplinas específicas. Nessa perspectiva, a proposta é a construção de um currículo baseado no lugar, que transcenda as disciplinas específicas, e no qual noções transculturais sejam importantes e consideradas. Neste momento, entendemos que os autores pensam uma realidade de países que já têm uma tradição em Educação ao Ar Livre, e que neste projeto, ao pensarmos no Brasil, estamos procurando estabelecer ligações entre as diferentes realidades escolares, sociais e econômicas. Refletimos sobre o fato de que em alguns momentos as práticas cotidianas precisamos trabalhar com as ferramentas e as possibilidades que possuímos. Nossa proposta era aplicar atividades que seriam possíveis de serem realizadas por outros professores em situação semelhante, adaptando para as suas realidades.

No segundo dia, caminhamos para uma pequena praça próxima à área da escola (cerca de setecentos metros), Praça 2, a praça tem uma área verde bastante interessante, onde algumas árvores estavam mostrando claramente as características da queda de suas folhas (estávamos no outono), o que não é algo comum em todas as árvores da região. Quando chegamos à praça, pedimos às crianças que criassem sua própria "Arte Natural Cooperativa". Surpreendentemente, essa foi uma atividade quando planejada com a professora, pensávamos que aconteceria de uma maneira muito simples, considerando, que estávamos trabalhando com alunos do segundo ano do Ensino Fundamental, mas a forma como os sujeitos alunos utilizaram os elementos naturais para construir suas artes foi bastante significativa. Uma atividade como essa explora diferentes sentidos dos sujeitos alunos, pois, a

ParaOnde!?, Porto Alegre, v.14, n.1, p.90-109, 2020.http://seer.ufrgs.br/paraonde 
textura e o toque dos materiais os estimula a pensar o que produzirão. Para essa atividade, as crianças foram convidadas, em grupos de seis, criarem um trabalho artístico utilizando as folhas, as rochas, os gravetos que pudessem encontrar na praça; os sujeitos alunos foram convidadas a pensar no conceito de sua arte e compartilhar sua produção com grupo em seguida, apesar de muito jovens, suas explicações sobre sua arte proporcionaram alguns dos momentos mais bonitos do projeto, muito inspiradores e poéticos (Figura 5).

Esse tipo de situação nos instiga a refletir em como as crianças podem ir além dos objetivos que haviam sido planejados. Um aspecto da Educação ao $\mathrm{Ar}$ Livre, que consideramos particular, é o fato de proporcionar uma experiência diferente com a temporalidade da ação. Frequentemente, nós professores estamos em uma velocidade acelerada para que consigamos lidar com as habilidades que planejamos, e algumas vezes, esses momentos de apreciação e criação não são respeitados ou nos causam certa angústia. Dessa forma, a Educação ao Ar Livre, nos faz refletir sobre o nosso tempo e práticas, explorando-as com um olhar mais tranquilo e espaçado- nos tornando autores.

Figura 5 - Arte Natural Cooperativa

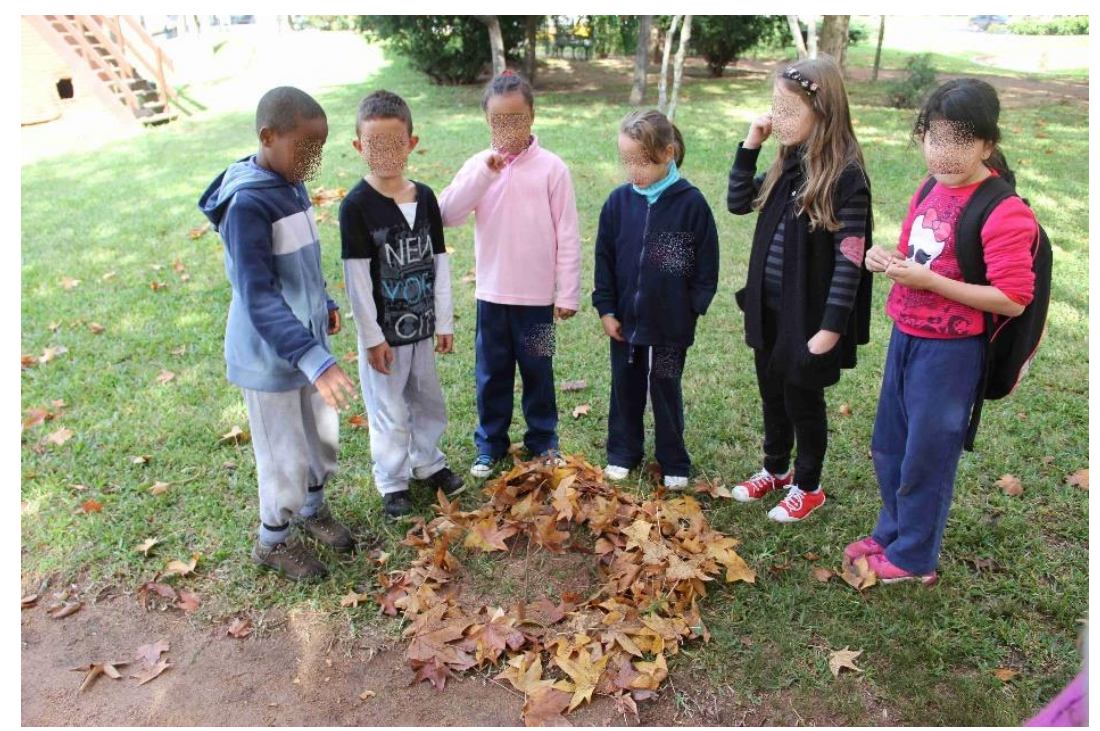

Fonte: Paola Gomes Pereira (2020)

No terceiro dia, caminhamos até a área próxima à margem do Lago Guaíba (número 2 na Figura 4). A atividade orientadora foi a Força-Tarefa para recolher resíduos. As crianças utilizaram luvas e sacolas plásticas, também eram recomendadas a não tocar na água, uma vez que essa parte do lago é imprópria para banho. Depois de coletar os resíduos por aproximadamente 30 minutos, o grupo sentou-se e cada uma das crianças teve que escolher um dos resíduos que havia coletado e explicar o caminho percorrido por aquele objeto até chegar naquele local. Essa foi uma etapa criativa, pois as crianças explicaram com detalhes as histórias por trás do desperdício daqueles objetos.

Aqui observamos como as crianças são capazes de associar o desperdício à sua vida cotidiana oferecendo uma chance de desenvolver senso de pertencimento ao lugar e perceber que as suas atitudes interferem onde moram. Talvez isso tenha dado a elas a possibilidade de ir além e refletir sobre como

ParaOnde!?, Porto Alegre, v.14, n.1, p.90-109, 2020.http://seer.ufrgs.br/paraonde 
podem interferir nos lugares onde elas e outras pessoas vivem. É uma atividade que, em nossa leitura, pode ser pensada como oportunidade para desenvolver 0 que chamamos, anteriormente, de um senso de lugar sem fronteiras, baseado em Massey (2005), um senso de lugar em que entendemos que a nossa existência depende de outros lugares e que a existência de outros lugares depende de nós. Outro resultado esperado, através de experiências como essa, é o que chamamos de responsividade ao lugar (WATTCHOW E BROWN, 2011). Refletimos sobre como momentos assim são significativos, pois é possível que teoria e prática se unam e mostrem as possibilidades de ensino e aprendizagem resultantes de um planejamento orientado por pressupostos teóricos específicos.

A "observação de pássaros" também foi praticada ainda no primeiro dia de atividades quando o grupo estava no parque ao lado da escola. A orientação para esta atividade foi direta: as crianças deveriam procurar pássaros entre as árvores no parque, em grupos de três. A qualquer momento que alguém do grupo encontrasse um pássaro deveria chamar silenciosamente a atenção de todos para que pudéssemos nos reunir e conversar sobre esse pássaro. A criança que encontrou o pássaro poderia dar um nome a ele, e discutíamos as suas principais características e se soubéssemos qual era o pássaro, apresentaríamos o nome e algumas características gerais. Mais tarde, as crianças desenharam o pássaro, então foram estimuladas a prestar atenção aos detalhes, olhar com carinho essa natureza. Em uma das situações, nós professores, não conhecíamos o pássaro que um dos grupos havia encontrado. Dissemos às crianças que pesquisaríamos sobre ele e traríamos as informações no dia seguinte. Ficamos muito felizes, pois, no dia seguinte, a primeira pergunta que a maioria dos alunos nos fez foi: "Vocês encontraram o nome do pássaro?". Isso demonstra a importância da situação para as crianças. Não foi apenas uma observação naquele momento, mas algo que permaneceram curiosos sobre. Este exemplo se conecta à pesquisa de Hattie (2012) em que o autor mostra a importância das expectativas dos alunos como uma das influências mais relevantes em suas aprendizagens. Vale ressaltar que as expectativas das crianças eram extremamente altas para todos os dias do projeto; nos dias em que o projeto teve que ser adiado, elas ficaram muito chateadas e, depois que as atividades começaram, sempre perguntavam se elas aconteceriam no dia seguinte ou não.

O quarto dia de atividades ocorreu no interior da área da escola. Esse momento foi significativo, sendo uma daquelas surpresas que emergem de situações imprevistas, pois em nosso planejamento anterior preferiríamos ter realizado atividades fora do espaço escolar. Nesse aula começamos com uma caminhada pelo pátio, mostrando alguns objetos existentes. $O$ pátio tinha muito lixo espalhado e gostaríamos de observar se as crianças iriam perceber e comentar tal aspecto, ou não. Em determinado momento, perguntaram sobre as características de uma árvore (Figuras 6 e 7), e então começamos a apresentar as árvores do pátio e refletir sobre o motivo delas terem musgo em algumas áreas e não em outras. Direcionamos a nossa discussão para uma observação dos meios de orientação e da incidência solar. Os sujeitos ficaram curiosos com o que puderam encontrar no pátio onde brincavam todos os dias e que, até então, nunca tinham percebido. Em nossa leitura, esse demonstra ser um dos objetivos de um projeto que proponha uma Educação ao Ar Livre voltada para o lugar: apresentar às crianças (ou adolescentes ou adultos) outras maneiras de ver o

ParaOnde!?, Porto Alegre, v.14, n.1, p.90-109, 2020.http://seer.ufrgs.br/paraonde 
lugar em que vivem e que experienciam diariamente. Algumas outras situações surgiram, como insetos que chamaram atenção, ou o pássaro morto encontrado, Figuras 8 e 9.

Figuras 6,7, 8 e 9 - Observação no pátio da escola

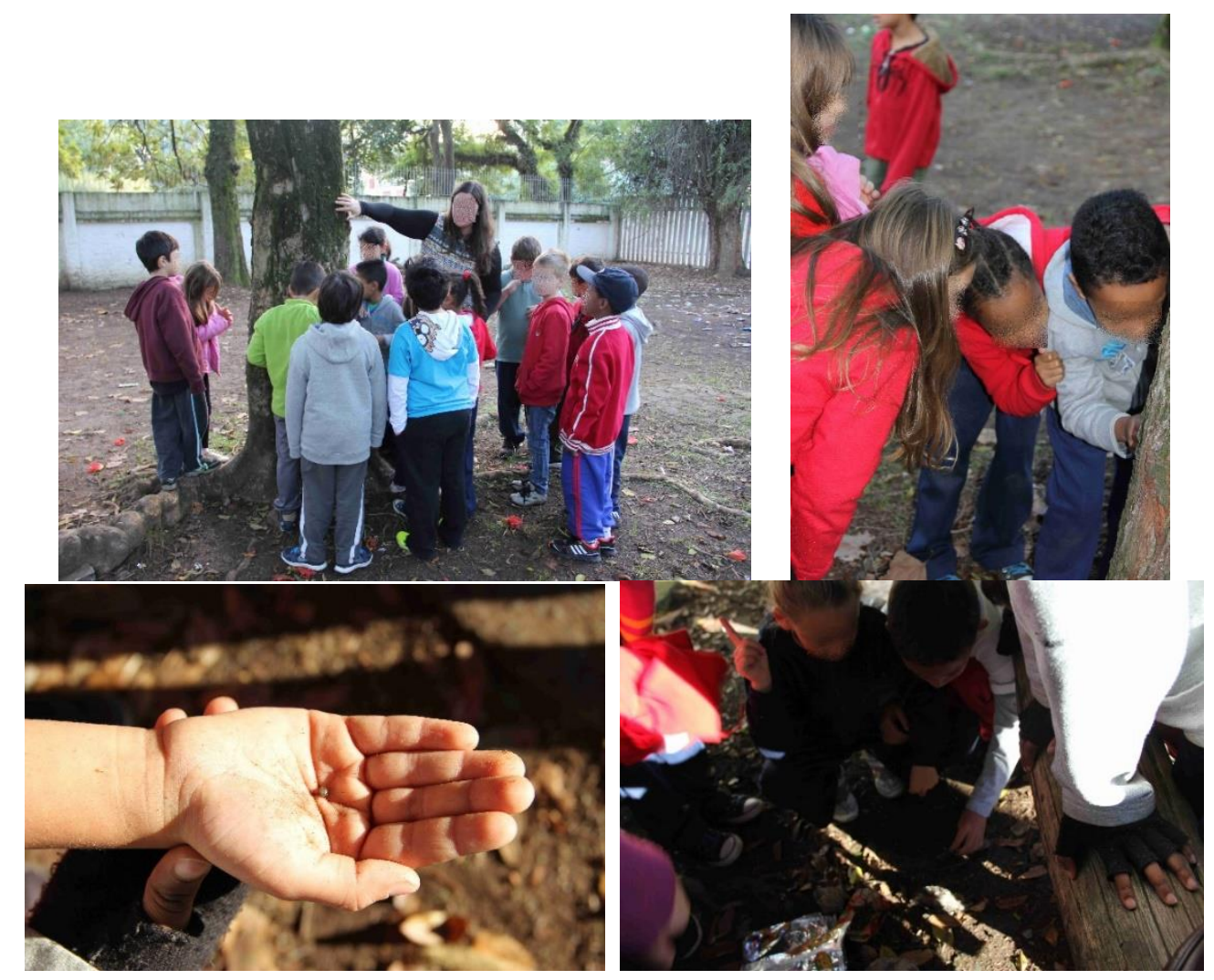

Fonte: Paola Gomes Pereira’ Antonio Carlos Castrogiovanni (2020)

Alguns dos momentos mais representativos do projeto não foram planejados especificamente, mas surgiram a partir das propostas executadas e entendemos que não poderiam deixar de ser mencionados. Como no momento em que o grupo estava próximo ao lago e um grande navio estava passando e surpreendeu a todos (na verdade não era um navio tão grande), mas aos olhos das crianças o tamanho pode ter uma mensuração bem diferente. Outro grande acontecimento do projeto para os sujeitos alunos, foi o momento em que um helicóptero estava pousando na praça em que o grupo estava. Mais uma situação peculiar aconteceu quando algumas formigas entraram nas pernas da professora e ela ficou muito nervosa. As crianças ficaram surpresas ao ver a professora em uma situação que ela não havia planejado e gostaram de observar o quão bem reagiu à situação. Esses situações podem nos parecer simples em um primeiro momento, mas nos perguntamos: quantas vezes na sala de aula é possível nos surpreendermos? Quantas vezes na sala de aula nos encontramos com o inesperado? Não apenas os alunos, mas também os professores, refletimos que, em apenas três dias de atividades fora da sala de aula tivemos essas situações atípicas, e que proporcionaram novas lógicas e formas de interação com o espaço e os seus sujeitos.

ParaOnde!?, Porto Alegre, v.14, n.1, p.90-109, 2020.http://seer.ufrgs.br/paraonde 
Neste momento, apresentaremos alguns dos resultados encontrados, através da análise e interpretação das metodologias desenvolvidas anteriormente.Para facilitar o processo de leitura, escolhemos abordar os resultados e a análise de forma conjunta. Mais uma vez lembramos que o objetivo não é alcançar noções e verdades fechadas, mas procurarmos nos desacomodar e encontrar diferentes maneiras e lógicas de pensar para analisar os processos, até então, tidos como únicos. O modelo da Teoria da Mudança (Figura 3) foi desenvolvido desde o início deste trabalho, portanto, será a principal ferramenta que auxiliará nessa busca por entender os resultados que emergiram dos grupos focais e dos desenhos criados pelo sujeitos alunos.

A primeira atividade no Modelo de Teoria da Mudança foi a de "Caminhada pela vizinhança". Dessa atividade, os resultados esperados eram uma conexão com o lugar e uma atitude responsiva com o lugar. Foi uma das menos mencionadas pelas crianças nos grupos focais. Elas estavam mais focadas em discutir situações específicas do que em falar sobre a caminhada. Embora nos desenhos tenha sido possível observar mudanças nas representações de algumas crianças, mostrando os locais pelos quais o grupo havia passado ao longo da caminhada nos desenhos feitos após as atividades, e que não estavam presentes nos desenhos anteriores. Essa situação nos faz refletir, que talvez, esperar uma atitude responsiva com o lugar, como resultado de uma atividade de caminhada através da vizinhança, pode ter sido um resultado muito complexo, para uma ação mais contemplativa. Entendemos que isso, não necessariamente signifique que essa atividade em conjunto as outras não tenha contribuído para alcançar esse resultado.

A atividade de "Observação de pássaros" nos parecia simples em um primeiro momento, e tinha como objetivo instigar as crianças a enxergar algo, em vez de apenas olhar sem intenção. A ideia era que eles trabalhassem com as suas habilidades de observação e concentração. E essa foi uma das atividades que trouxe alguns dos resultados interessantes, como observamos nos grupos focais. Para facilitar o entendimento das mudanças evocadas por esta atividade traremos como exemplo um dos alunos.

A professora da turma e a direção haviam mencionado, no início do projeto, que uma das crianças tinha algumas questões comportamentais e que deveríamos prestar atenção a ele durante as saídas da escola. $\mathrm{Na}$ atividade 'Observação de pássaros', notamos uma mudança de comportamento de seus colegas de turma em relação a esse aluno, uma vez que ele era muito observador e conseguia encontrar pássaros com relativa facilidade, dessa forma ele tornou-se o localizador de pássaros do grupo e isso lhe trouxe sensação de pertencimento bastante interessante durante as práticas. Mais tarde, nos grupos focais que aplicamos com as crianças, esse sujeito aluno demonstrou mais uma vez que algumas das mudanças trazidas por essa atividade ainda estavam presentes, dizendo que "Quando tivemos o dia de observação de aves, eu me saí muito bem. Eu sempre fui o primeiro a encontrar pássaros". Em entrevista semiestruturada com a professora ela mencionou que, após a visita de campo, esse aluno, havia se tornado um pouco mais independente em suas atividades cotidianas e se relacionava melhor com seus colegas de classe. Isso nos mostra que, embora habilidades sócio-emocionais não tenham sido planejadas como resultados para essa atividade específica, a "observação de pássaros"

ParaOnde!?, Porto Alegre, v.14, n.1, p.90-109, 2020.http://seer.ufrgs.br/paraonde 
conseguiu proporcionar ao garoto um pouco mais de confiança nas interações sociais.

A situação nos instiga a refletir sobre o fato de que dentro das salas de aula, algumas das habilidades de nossos alunos podem não encontrar espaços e situações para aparecerem e, talvez, existam maneiras diferentes de fazermos as coisas, novos olhares para vermos e entendermos nossos alunos, novos espaços que permitam a eles desenvolverem e apresentarem habilidades até então silenciadas. Proporcionando-lhes novas chances de aprender e de se relacionar consigo mesmos e com os outros.

A " força-tarefa para recolher resíduos" foi a atividade, que em nossa leitura, apresentou os resultados mais facilmente reconhecíveis. Tínhamos dois resultados planejados: "senso de comunidade" e "senso de pertencimento". Os dois poderiam ter um impacto nos três resultados indiretos do projeto "atitude responsiva com o lugar", "diminuição do individualismo" e "maior confiança". O senso de comunidade e o sentimento de pertencimento foram percebidos, mesmo quando estávamos na atividade, pois, as crianças trabalhavam juntas e se ajudavam de uma forma muito natural, elas também diziam coisas como "Será que podemos fazer isso onde moramos?". Questões como essa demonstraram, como sentiram-se pertencentes ao lugar e que entendiam que também eram responsáveis por isso, como no momento em que disseram "fazemos isso" e não "eles fazem isso". Os grupos focais foram uma ferramenta importante para retomarmos e percebermos se essas reflexões eram uma preocupação momentânea para os alunos, ou se ainda estavam presentes após duas semanas de sua aplicação. Nos três grupos, apareceram comentários sobre a "Força-tarefa para recolher resíduos", e a atividade foi citada especificamente, quando nos grupos focais foi feita a seguinte pergunta: "O que fez você se orgulhar do projeto?", as crianças fizeram esse pequeno diálogo que consideramos interessante:

"Aluna 1: Nós fizemos muito bem. Ajudamos com o lixo.

Aluno 2: Mas não ajuda se for apenas uma vez.

Aluna 3: Sim, devemos fazer isso mais vezes.

Aluno 4: Mas lembram que dissemos que não ajuda se continuarmos jogando coisas fora " (Retirado das transcrições dos grupos focais)

Compreendemos que um diálogo como esse mostra que, mais do que se orgulhar da força-tarefa, as crianças perceberam que deveriam continuar com o trabalho e mudar as ações que causaram a situação que haviam encontrado. Entendemos a capacidade de resposta do local como um resultado substancial de aprendizado alcançado, pois as crianças sentiram e expressaram que eram responsáveis por esse local. A situação também cria uma conversa com as habilidades orientadas pela atual BNCC (BRASIL, 2018), onde algumas noções como a compreensão da cidadania e o respeito pelo outro e pelo meio ambiente estão presentes. Na verdade, a maioria das habilidades geográficas sugeridas pelo documento poderiam ser alcançadas por meio de atividades ao ar livre, e isso, em nossa leitura, não significa que não possam ser desenvolvidas em outras situações de sala de aula, mas refletimos que o grupo focal demonstrou que, mesmo após duas semanas, noções relevantes ainda estavam presentes para os sujeitos alunos, e isso é bastante representativo. Além disso, uma das

ParaOnde!?, Porto Alegre, v.14, n.1, p.90-109, 2020.http://seer.ufrgs.br/paraonde 
nossas reflexões era: e se os alunos tiverem aulas regulares na sala de aula? Seria diferente de sair, caminhar até o lago, coletar o lixo, se envolver fisicamente nisso? De refletirem sobre um objeto concreto que eles coletaram? Existe uma diferença entre aprender os mesmos assuntos em ambientes diferentes? Segundo Cory-Wright (2010), há uma diferença no processo de aprendizagem envolvido nessas situações, quando as crianças estão aprendendo fora da sala de aula e engajadas fisicamente na atividade, seu processo de aprendizagem é mais profundo e significativo.

A quarta atividade para analisarmos é a "arte natural cooperativa". Essa foi uma das mais mencionadas pelas crianças, sempre que nós perguntávamos qual foi a sua parte favorita da semana. A maioria das crianças disse que essa atividade era muito agradável e que realmente gostaram de apresentar sua arte. Uma das alunas, mencionou "gostei quando apresentei nossa arte, para que todos pudessem entender o que nosso grupo queria dizer com isso". Um dos resultados esperados dessa atividade foi uma melhor compreensão do ambiente natural e, embora aspectos diretos, não tenham sido mencionados pelos sujeitos nos grupos focais, durante o dia em que estávamos aplicando a atividade percebemos que as crianças perguntavam sobre as folhas e as sementes que elas puderam encontrar no chão. Na segunda parte da atividade, quando explicamos sobre a estação do ano em que nos encontrávamos, as crianças, fizeram muitas perguntas e apresentaram contribuições. O senso de comunidade, também estava presente As crianças trabalhavam muito bem em seus grupos, discutiam sobre possibilidades de sua arte e eram muito compreensivas com os motivos umas das outras em influenciar no trabalho que estavam fazendo conjuntamente, mostrando que era um tipo de atividade em que eles poderiam trabalhar juntos sem nenhum sentimento de competição, mesmo que grupos diferentes criassem artes diferentes. Este exemplo se conecta à sugestão de Hattie (2012) em que indica as possibilidades de aprendizagem cooperativa e individual, como um dos elementos que influencia consideravelmente as realizações dos sujeitos alunos.

Uma pergunta levantada durante os grupos focais foi: "Qual foi a maior aventura do projeto?". Nossa proposta principal era tentar entender se as crianças poderiam perceber desafios em um projeto de Educação ao Ar Livre voltado ao lugar, e que não propunha atividades com riscos elevados. Várias respostas foram dadas. Algumas das crianças comentaram que a parte mais difícil foi quando tiveram que descer e subir um pequeno barranco (realmente muito pequeno, é possível observá-lo ao fundo da Figura 2). Essa situação, nos permite refletir sobre como pequenos desafios para nós adultos, podem ter um grande impacto aos olhos das crianças, e muitas vezes, nos esquecemos disso. Outro momento que eles mencionaram como uma grande aventura foi quando deveriam atravessar uma ponte com cerca de 5 metros para cruzar um pequeno riacho em uma praça. O que para nós pode parecer pequeno, foi um momento destacado pelos sujeitos alunos de todos os grupos. Simultaneamente, um aluno que disse que o barranco para ele tinha sido muito fácil, comentou que o seu maior desafio foi atravessar uma grande avenida, portanto isso nos demonstra que a definição se algo é ou não, uma aventura, depende do sujeito que a está experienciando.

ParaOnde!?, Porto Alegre, v.14, n.1, p.90-109, 2020.http://seer.ufrgs.br/paraonde 


\section{Considerações Finais}

Como mencionamos, com este trabalho não objetivávamos chegar a conclusões fechadas e encontrar respostas padronizadas. Embora isso não signifique que não possamos trazer algumas considerações alcançadas e discussões construtivas. A primeira consideração que pensamos pertinente, é refletirmos sobre como um estudo transcultural pode nos estimular a busca novas lógicas, nas quais através do diálogo, com outras formas de ensinar e aprender, podemos nos reinventar enquanto professores e pesquisadores. Um aspeto interessante é o fato de buscarmos trocas com autores que possuem origens distintas, principalmente fazendo um exercício de dialogar com práticas comuns em países anglo-saxões.

Considerando os três resultados indiretos, planejados a partir do modelo de Teoria da Mudança, que foram uma atitude responsiva com o lugar, menos individualismo e maior confiança. Consideramos que através das análises realizadas, nos parece possível, nesse momento, observar que eles foram parcialmente alcançados e que por fazerem parte de um processo muito mais amplo e continuo, é razoável compreender, que em uma semana de atividades isso não poderia ser plenamente alcançado, mas proporcionado um encaminhamento para tal. Para alcançarmos resultados como esses, é necessário considerarmos práticas e projetos contínuos. O objetivo é mostrar como um projeto de Educação ao Ar Livre baseado no lugar pode ser implementado na realidade brasileira e inspirar novas práticas que possam estimular resultados ao longo do processo de aprendizagem. Refletimos sobre a necessidade de ter um maior apoio para a aplicação de atividades como estas. A professora da turma mencionou que ficou surpresa com o quão calmo e fácil foi realizarmos as atividades fora da escola. A professora indicou que, se pudesse ter o apoio de alguém que fosse uma semana por trimestre, poderia planejar projetos como esse com periodicidade. Isso nos lembra o fato de que nós mesmos enquanto professores temos uma preocupação muito grande com atividades que ocorrem fora do espaço escolar, mas que de maneira geral elas ocorrem de forma muito mais tranquila do que antecipamos.

Considerando a particularidade do projeto não tivemos a oportunidade de pensar em resultados que incluíam habilidades de alfabetização. Mas entendemos, que seria possível elaborar um plano para um ano letivo, com duas ou três semanas ao longo do ano para desempenhar atividades ao ar livre voltadas para o lugar e que também incorporassem os diferentes campos do conhecimento inseridos no processo de alfabetização e letramento.

Refletimos sobre importância não é apenas do que fizemos efetivamente, mas também de considerarmos o que é possível de ser desenvolvido a partir disso. Os resultados do projeto nos inspiraram enquanto professores a buscarmos mais práticas ao ar livre e, posteriormente, este trabalho pode influenciar outros professores e educadores a adaptá-lo às suas realidades.

Projetos como este nos parecem relevantes em grandes áreas urbanas, onde a desconexão com a natureza é aparentemente mais perceptível e sentida pelos habitantes. A necessidade de uma apropriação significativa do espaço geográfico nos parece evidente, e as experiências proporcionadas pelas práticas ao ar livre podem ser ainda mais expressivas nesses lugares. $O$ uso de locais

ParaOnde!?, Porto Alegre, v.14, n.1, p.90-109, 2020.http://seer.ufrgs.br/paraonde 
como os parques da cidade, as praças e as margens do lago, permitiram aos sujeitos alunos uma compreensão mais ampla, de que esses espaços públicos também pertencem a elas e que elas podem fazer seu uso, e que são responsáveis pela sua manutenção. No caso de Porto Alegre, podemos mencionar a prática recorrente de uma cidade que, por vezes, aparentemente esquece seu lago. Mesmo considerando as atividades desenvolvidas neste projeto, observamos que o lago era o principal foco em apenas uma delas e isso instiga o pensamento sobre novas práticas que venham a ampliar os usos recreativos e pedagógicos do lago, que possui um grande significado para a cidade, mas muitas vezes é esquecido por seus habitantes. Pensamos que para novos projetos, podem vir a serem pensadas iniciativas com espaços que oferecem oportunidade de praticar atividades como canoagem e remo, a fim de estabelecer parcerias para projetos de Educação ao Ar Livre voltada para o lugar.

Outro aspecto é a forma como pensamos o projeto. Muitas vezes observamos atividades sendo realizadas de maneira pontual, com um ou dois dias de saídas da escola, com objetivos e conteúdos bastante específicos. Pensamos que a efetiva aplicação de uma Educação ao Ar Livre, nos exige um tempo diferente, a continuidade é necessária, e o tempo de maturação para a apreciação dos alunos também. De certa forma, pensamos que a Educação ao Ar Livre, apareça como um movimento que nos instigue desacelerar e redescobrir o espaço geográfico que ocupamos e construímos.

Indicamos a presença no Brasil de algumas empresas e organizações que utilizam atividades ao ar livre para oferecer a seus participantes a chance de desenvolverem habilidades profissionais orientadas para os negócios. Não buscamos nesse trabalho discutir esse formato de atividade, mas lembramos que a proposta foi estabelecer práticas de ensino e aprendizagem, em que procuramos compreender a constituição dos sujeitos alunos como cidadãos na busca por trabalhar com a sociedade e não apenas pensando em transformações individuais.

Neste momento, indicamos que o envolvimento dos sujeitos alunos nessa pesquisa foi uma inspiração substancial. Participar do projeto não era apenas algo que eles deveriam fazer, mas algo que eles esperavam e ansiavam por fazer. Entendemos que esse envolvimento com o que está sendo aplicado demonstrou relevante importância nos resultados obtidos. Ao chegarmos todos os dias na escola, e encontrarmos alunos curiosos e com expectativas diversas sobre o que iria acontecer fez com que as práticas adquirissem um novo significado. Decidimos refletir sobre as noções e ideias aqui desenvolvidas e apresentadas como possibilidades para continuarmos trabalhando com a educação e refletirmos sobre novas maneiras de proporcionar processos de ensino e aprendizagem.

\section{Referências}

BAUER, Martin W.; GASKELL, George. Pesquisa qualitativa com texto, imagem e som: um manual prático. 4. ed. Petrópolis: Vozes, 2005.

BAUMAN, Zygmunt. Liquid Modernity. Cambridge: Polity Press, 2000.

BRASIL. Parâmetros curriculares nacionais - Ensino Fundamental 1. Brasília:

ParaOnde!?, Porto Alegre, v.14, n.1, p.90-109, 2020.http://seer.ufrgs.br/paraonde 
MEC.

1997

Disponível:

em:

http://portal.mec.gov.br/seb/arquivos/pdf/CienciasHumanas.pdf. Acesso 06 jun 2014

BRASIL. Base Nacional Comum Curricular (BNCC). Brasília: MEC. 2018. Disponível

em: http://basenacionalcomum.mec.gov.br/BNCC_EI_EF_110518_versaofinal_site. pdf Acesso 01 jul 2019

CALLAI, Helena. Estudar o lugar para compreender o mundo. In: Castrogiovanni, Antonio Carlos (Org.). Ensino de geografia: práticas e textualizações no cotidiano. 8 ed. Porto Alegre: Mediação 2010.

CASTROGIOVANNI, Antonio Carlos. Apreensão e compreensão do espaço geográfico. In: Castrogiovanni, Antonio Carlos (Org.). Ensino de geografia: práticas e textualizações no cotidiano. 8 ed. Porto Alegre: Mediação, 2010.

CAVALCANTI, Lana de Souza. O lugar como espacialidade na formação do professor de geografia: breves considerações sobre práticas curriculares. Revista brasileira de educação em Geografia, 1(2), 1-18. 2011.

CORY-WRIGHT, Jean. Adapting Group Initiative and Problem Solving Activities to enhance deep learning. Education Outdoors New Zealand, 23, p.14.17. 2010.

FLICK, Uwe. Introdução à metodologia de pesquisa: um guia para iniciantes. Tradução: Magda Lopes; Revisão Dirceu da Silva. Porto Alegre: Penso: 2013.

HATTIE, John. Visible learning for teachers: maximizing impact on learning. London: Routledge, 2012.

LOYNES, Chris. The British Youth Expedition: Cultural and Historical Perspectives. In Beames, S. (ed.) Understanding Educational Expeditions. Rotterdam: Sense Publishers, 2010.

MANNION, Greg; ADEY, Claire; LYNCH, Jonathan. Intergenerational Placebased Education: where schools, communities, and nature meet. Stirling: University of Stirling for Scottish Centre for Intergenerational Practice, 2010

MCNEIL, Bethia; REEDER, Neil; RICH, Julia. The young foundation: A framework of outcomes for young people. 2012. Disponível em:https://www.gov.uk/government/uploads/system/uploads/attachment_data/fil e/1 75476/Framework_of_Outcomes_for_Young_People.pdf Acesso 02 Maio 2014.

MASSEY, Doreen. Space, Place and Gender. 3. ed. Minneapolis: University Of Minnesota Press, 2001.

MASSEY, Doreen. Power-geometry and a progressive sense of place in Bird, J. et al (Eds.) Mapping the futures: local cultures, global change. (pp.60-70) New York: Routledge, 2005.

MORIN, Edgar. Da necessidade de um pensamento complexo. In: MARTINS, Francisco Menezes; SILVA, Juremir Machado da. Para navegar no século 21: tecnologias do imginário e cibercultura. Porto Alegre: Sulina, 1999. p. 19-42.

PEREIRA, Paola Gomes. A educação ao ar livre voltada para o lugar e suas possibilidades no ensino de geografia. In: CASTROGIOVANNI, Antonio Carlos

ParaOnde!?, Porto Alegre, v.14, n.1, p.90-109, 2020.http://seer.ufrgs.br/paraonde 
et al. Movimentos no ensinar geografia: rompendo rotações. Porto Alegre: Evangraf, 2015. p. 141-155.

SANTOS, Milton. A Natureza do Espaço. 4ed. São Paulo: EDUSP, 2004.

TUAN, Yi-fu. Topofilia: um estudo da percepção, atitudes e valores do meio ambiente. São Paulo: Difel, 1980.

TUAN, Yi-fu. Space and Place: The Perspective of Experience. 8 ed. Minneapolis: University of Minnesota Press, 2001.

WATTCHOW, Brian; BROWN, Mike. A Pedagogy of Place: Outdoor education for a changing world. Clayton: Monash University Publishing, 2011. 